\title{
Reduction of Damping Oscillations of Power Systems with Combinational Operation of LFC \& AVR in Single Area
}

\author{
Jyothilal Nayak Bharothu*, G Venkatesh \\ Associate professor of Electrical \& Electronics Engineering, Sri Vasavi Institute of Engineering \& Technology, Nandamuru, India \\ *Corresponding author: nayakeee@gmail.com
}

Received September 16, 2013; Revised October 22, 2013; Accepted January 16, 2014

\begin{abstract}
The main aim of this paper is to reduce the damping oscillations. In this paper a new model is proposed to show the interaction between load frequency oscillations and automatic voltage regulator loops and to achieve more accuracy in dynamic and steady state response. The major problem arising from large scale electric power system interconnection is the low frequency oscillation of interconnected system. In order to maintain all the scheduled power transactions to the constant value, automatic generation control of a power system with closed loop feedback is used. By using the data acquisition system which conducts the actual operating conditions of the systems and the errors are computed. In ordered to maintain the level of voltage and frequency automatic generation control method through LFC loops is used.
\end{abstract}

Keywords: damping oscillations, LFC, AVR, MAT LAB, Simulink

Cite This Article: Jyothilal Nayak Bharothu, and G Venkatesh, "Reduction of Damping Oscillations of Power Systems with Combinational Operation of LFC \& AVR in Single Area.” American Journal of Electrical and Electronic Engineering 2, no. 2 (2014): 27-39. doi: 10.12691/ajeee-2-2-1.

\section{Introduction}

One of the most important stability problems arising from large-scale electric power system interconnections is the low frequency oscillation of interconnected systems. The low-frequency oscillations are attributed to the oscillations of the mechanical mode of the system and can be approximately analyzed with a linear one-machine infinite bus model [1]. A complete system model for lowfrequency oscillation studies must be included of mechanical and electrical loops. It has been recognized that these oscillations can be controlled by adjusting exciter and speed-governor control parameters. Furthermore, it has been shown that the Load-voltage characteristic of the power system has a significant effect on its dynamic responses, and suggestions have been made for the proper representation of these characteristics in simulation studies [2,3]. In practice, Automatic Generation Control of a power system is a set of equipment and computer programs that applies closed loop feedback control to regulate the power system frequency to a scheduled value, to maintain all scheduled power transactions to the contract value as well as the net power interchange at the value required by the interchange contracts, and to maintain each generation unit's operation at the most economic value (Economic Dispatch).

Modern automatic generation control functions are performed at a central location, the Energy Management System (EMS) or the Control Center. The AGC is driven by the scheduled frequency and the scheduled net interchange of the controlled entity. The data(errors)are computed $[4,5,6]$. The errors are used to determine the control signals to the individual generators in such a way that the frequency returns to the scheduled value and the power transactions are regulated to the scheduled value. A lot of studies have been made about LFC over the last decades but these researches don't have any attention to AVR effects on the results $[7,8]$. The two main control loops of a generation care Load Frequency Controller (LFC) and Automatic Voltage Regulator (AVR) as seen in Figure 1.1.

The turbine fed by controllable rate of steam and the Automatic Generation Control method deals with frequency through the LFC loop and with voltage through with the AVR loop, where the main purposes of these controllers are to maintain levels of voltage end frequency at the acceptable values. However, these studies are based on the assumption that there is no interaction between the power/frequency and the reactive power/voltage control loops. This assumption is permissible acquisition system collects the actual operating conditions of the system and the deviations only when the speed of the excitation system is much faster than that of the LFC system; in the practical systems, during dynamic perturbations, exists some interaction between these two control channels due to the weak coupling relationship between the AVR and LFC, the voltage and frequency are regulated separately.

The study of coupling effects of the AVR and LFC loops can be found in [6] and [9]. But in all of these researches there are sketchy attentions to these mutual 
effects. Furthermore there is no any attention to the turbine output power in the steady state. Also, by neglecting the effect of voltage deviation on load demand, an important interaction in LFC systems is ignored. In order to prevent this problem and improve the accuracy of responses in this paper, a new combined classical model is proposed. A complete system model for low.

Frequency oscillation studies must be included of mechanical and electrical loops. So single machine infinite bus model of a power system is combined to load frequency control system.

This proposed combined model is tested on one-area power system. Simulation results are shown that there are mutual effects between LFC and excitation system. Furthermore the results are shown that by using this model for low-frequency oscillation study of power systems, more accuracy will be reachable in dynamic and steady state responses.

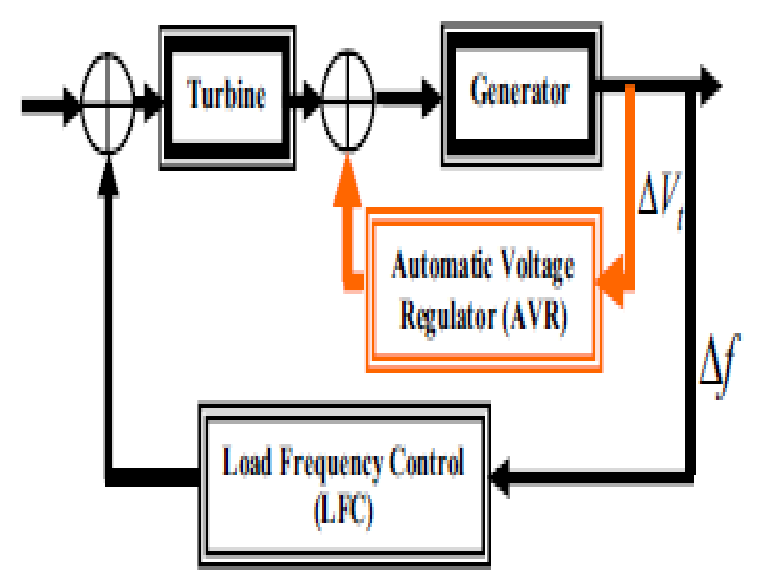

Figure 1.1. Automatic generation control with LFC and AVR loops

\section{Load Frequency Controller}

\subsection{Introduction}

The generation of power units and consumption of loads connected to the UCTE network needs to be controlled and monitored for secure and high-quality operation of the synchronous areas. The load frequency control, the technical reserves and the corresponding control performances are essential to allow TSOs to perform daily operational business. Within the UCTE synchronous area, the control actions and the reserves are organized in a hierarchical structure with control areas, control blocks and the synchronous area with two coordination centers. UCTE Pyramid in Policy Coordination Center (UCTE South) Control Block Control Block Control Area Control Area Control Area Coordination Center (UCTE North) Control Block Control Block Control Area Control Area Control Area Figure 1.1 Hierarchical control structure of UCTE synchronous area composed of control areas (ca), control blocks (cb) and co-ordination centers (cc) Control actions are performed in different successive steps, each with different characteristics and qualities.

Control scheme and actions starting with the system frequency primary control starts within seconds as a joint action of all parties involved. Secondary control replaces primary control over minutes and is put into action by the responsible parties / TSOs only. Tertiary control partially complements and finally replaces secondary control by rescheduling generation and is put into action by the responsible parties / TSOs. Time control corrects global time deviations of the synchronous time in the long term as a joint action of all parties / TSOs. On the time axis, the different control reserves cover different time frames the principles, how in case of an incident with a large frequency drop (the dotted Line beginning before activation of Primary Control shows the principle plot of the frequency Deviation) the activation of primary control reserve (activated within seconds) is followed up by secondary control reserve (activated within minutes) and secondary control reserve is supported and followed up by tertiary control reserve. UCTE OH - Policy 1: LoadFrequency Control - Final Version (approved by SC on 19 March 2009) Time directly activated Tertiary Control Reserve Schedule activated Tertiary Control Reserve Activated Secondary Control Reserve UCTE-wide activated Primary Control Reserve.

Principle frequency deviation and subsequent activation of reserves The "TSO-Forum" (organized by the UCTE WG "Operations \& Security") serves as the Common body in the UCTE of all TSOs for all operational and organizational items in the Framework of Load-Frequency Control and Performance. Please refer to the glossary of terms of the UCTE Operation Handbook for detailed definitions of terms used within this policy and to Appendix 1 for basics and principles of load-frequency control and performance.

This version of the document (version 3.0, level C, dated 12.03.2009) has "rev15" status. This document and other chapters of the UCTE Operation Handbook as well as excerpts from it may not be published, redistributed or modified in any technical means or used for any other purpose outside of UCTE without written permission in advance. UCTE OH - Policy 1: Load-Frequency Control Final Version (approved by SC on 19 March 2009)

\subsection{Primary Control}

The objective of primary control is to maintain a balance between generation and consumption (demand) within the synchronous area. By the joint action of all interconnected parties / TSOs, primary control aims at the operational reliability of the power system of the synchronous area and stabilizes the system frequency at a stationary value after a disturbance or incident in the timeframe of seconds, but without restoring the system frequency and the power exchanges to their reference values. Adequate primary control depends on generation or load resources made available to the TSOs basics and principles of primary control. Nominal Frequency.

The nominal frequency value in the synchronous area is $50.000 \mathrm{~Hz}$. The set-point frequency (or scheduled frequency) fo defines the target value of the system frequency f for system operation. Outside periods for the correction of synchronous time the scheduled frequency is the nominal frequency. Frequency Levels and Frequency Deviations.

A frequency deviation away from the nominal frequency results from an imbalance between generation 
and demand that occurs continually during normal system operation or after an incident like a loss of generation. a frequency deviation results from an unwanted imbalance between generation and demand. Different criteria are used to distinguish the size of this deviation: A-D2.1. Activation of primary control.

Primary control activation is triggered before the frequency deviation towards the nominal frequency exceeds20 MHZ (the sum of the accuracy of the local frequency measurement and the insensitivity of the controller maximum permissible quasi-steady-state frequency deviation after reference incident. a quasisteady-state frequency deviation of $180 \mathrm{MHZ}$ away from the nominal frequency is permitted as a maximum value in the UCTE synchronous area after occurrence of a reference UCTE oh - policy 1: load-frequency control final version incident after a period of initially undisturbed operation. when assuming that the effect of self-regulation of the load is absent, the maximum permissible quasisteady-state deviation would be $200 \mathrm{MHZ}$ this deviation causes full activation of primary control within the UCTE synchronous area and (passive) self-regulation of load.

Minimum instantaneous frequency after loss of generation. the minimum instantaneous frequency is defined to be $49.2 \mathrm{~Hz}$ (that corresponds to $-800 \mathrm{MHZ}$ as maximum permissible dynamic frequency deviation from the nominal frequency in response to a shortfall in generation capacity equal to or less than the reference incident according to. maximum instantaneous frequency after loss of load. the maximum instantaneous frequency is defined to be $50.8 \mathrm{hz}$ (that corresponds to $+800 \mathrm{MHZ}$ as maximum permissible dynamic frequency deviation from the nominal frequency $\mathrm{p} 1-\mathrm{A}-\mathrm{D} 1)$ in response to a loss of load or interruption of power exchanges equal to or less than the reference incident according to p1-A-D3.1. AD2.5. full activation of primary control reserves. in case of a quasi- steady state deviation of the system frequency of $200 \mathrm{MHZ}$ from the nominal frequency, all available primary control reserves are expected to be fully activated. A-D3. reference incident.

The maximum instantaneous power deviation between generation and demand in the un-split synchronous area (by the sudden loss of generation capacity or loadshedding / loss of load) to be handled by primary control starting from undisturbed operation depends on the size of the synchronous area and of the largest generation unit or generation capacity connected to a single bus bar. A-D3.1. reference incident for the UCTE synchronous area for the UCTE synchronous area the maximum instantaneous power deviation is defined to be $3000 \mathrm{MW}$, based on operational characteristics concerning system reliability and size of loads and generation units 2 .

Observation Incident Size for System Response Analysis. Large incidents, such as the sudden loss of generation or load, that exceed $600 \mathrm{mw}$ (first level) respectively $1000 \mathrm{mw}$ (second level) in the UCTE synchronous area, trigger a UCTE system response analysis procedure. A-D4. primary control characteristics.

The following key values of the primary control UCTE oh - policy 1: load-frequency control - final version p1-6 A-D4.1. Self-regulation of load. the self-regulation of the load in the UCTE synchronous area is assumed to be $1 / \mathrm{hz}$, that means a load decrease of $1 \%$ occurs in case of a frequency drop of $1 \mathrm{hz}$. see a1-e for the calculated network power frequency characteristic of self regulation for the UCTE synchronous area. A-D4.2. quasi steadystate security margin. for frequency control, the quasi steady-state security margin is defined to be $20 \mathrm{MHZ}$ AD4.3. Minimum network power frequency characteristic of primary control. the minimum network power frequency characteristic of primary control for the UCTE synchronous area is calculated out of p1-A-D3.1 and (including the security margin p1-A-D4.2) to 15000 $\mathrm{MW} / \mathrm{HZ}$. A-D4.4. average network power frequency characteristic of primary control. on average, the network power frequency characteristic of primary control is experienced to be $30 \%$ higher than the minimum network power frequency characteristic of primary control, that results on average to $19500 \mathrm{MW} / \mathrm{HZ}$. A-D4.5. surpluscontrol of generation. The surplus-control of generation is an experienced linear responses of approximately $50 \%$ of all generation units reacting to frequency deviations. this results in an additional value of self-control of generation, that is calculated based on the mean generation power in the system (see a1-e for the calculated values). This surplus control of generation exists in addition to the minimum network power.

\subsection{Characteristic of Primary Control}

Overall network power frequency characteristic. The overall network power frequency characteristic for the UCTE synchronous area is the sum of contributions from primary control of $19500 \mathrm{MW} / \mathrm{HZ}$, the surplus-control of generation and self regulation of load for the up-to-date value of the overall network power frequency characteristic for the UCTE.

\subsubsection{Synchronous Area}

Overall primary control reserve. With respect to the size of the reference incident of $3000 \mathrm{mw}$ the overall primary control reserve for the UCTE synchronous area is agreed to be 3000 mw. Load-frequency control - final version. Primary control reliability and target. in case of a first contingency or incident according to, such as the loss of generation or load or interruption of power exchanges in an undisturbed situation, primary control must maintain reliable system operation. starting from undisturbed operation a reference incident must be handled by primary control alone, without the need for under-frequency automatic load-shedding or disconnection of generation in response to a frequency deviation. Primary control organization. an organizational procedure to cover requirements and obligations for primary control actions and reserves performed by third parties in the control area including a monitoring procedure must be in place (e.g. grid code, regulation, association agreement or contract).

Primary control action by generators or loads. the action of the generators or loads performing primary control must have the following characteristics, to be ensured by all tsos:a-s2.1. Accuracy of frequency measurements. for primary control, the accuracy of local frequency measurements used in the primary controllers must be better than or equal to $10 \mathrm{MHZ}$. Adjustment of power and insensitivity of controllers.

Power under primary control must be proportionally adjusted to follow changes of system frequency. The insensitivity range of primary controllers should not 
exceed $\pm 10 \mathrm{MHZ}$ where dead bands exist in specific controllers, these must be offset within the control area / block concerned.. physical deployment times. the time for starting the action of primary control is a few seconds after the incident, the deployment time for $50 \%$ or less of the total primary control reserve is at most 15 seconds and from $50 \%$ to $100 \%$ the maximum deployment time rises linearly to 30 seconds. Each tso must check the deployment times within his control area / block on a regular basis. by this, the total primary control within the entire synchronous area (as well as within each control area /block) follows the same deployment times. Duration of delivery. Primary control power must be delivered until the power deviation is completely offset by the secondary / tertiary control reserve of the control area / block in which the power deviation has occurred UCTE oh policy 1: load-frequency control - final version. Joint action for primary control. Primary control is based on the principle of joint action to ensure system reliability and interconnected operation.

This includes an overall distribution of reserves and control actions, as determined and decided by the "tsoforum" on an annual basis for the next calendar year contribution to primary control reserve. The total primary control reserve (in $\mathrm{mw}$ ) required for operation of the UCTE synchronous area is of the same size as the reference incident. Each control area / block must contribute to the primary control reserve proportionally, so that the sum of all shares amounts to the total required primary control reserve. the respective shares (mandatory primary control reserves) are defined by multiplying the overall primary control reserve for the entire synchronous area and the contribution coefficients of the various control areas / blocks (see. any control area can increase its primary control reserve by $30 \%$ by offering to cover (part of) the obligations of other control areas. however, every control area is allowed to increase its primary control reserve by $90 \mathrm{mw}$ to cover the obligations of other control areas (which is approx. $3 \%$ of total UCTE primary control reserve and corresponds to the limitation for loss of primary a-s3.2. contribution to primary control action.

Each control area / block must contribute to the correction of a disturbance in accordance with its respective contribution coefficient for primary control. Limitation for loss of primary control reserve. if a generator, on which primary control reserve is allocated, trips, the immediate loss of primary control reserve must be limited to $90 \mathrm{mw}$ or $3 \%$ of the reference incident size (by this the decline of the network power FREQUENCY characteristic will be limited).

Responsibilities in the process. each reserve connecting to is responsible for the primary control contribution of the control area, including cross-border primary control contributions for other control areas. This includes the contribution, the monitoring, the general procedure and the information exchange for primary control reserve. Information exchange between tsos the reserve receiving tso communicates to the reserve connecting tso by which amount the value of its k-factor must be increased or decreased before the beginning or termination of any exchanging transaction of power for primary control. In the case of transactions within a control block with pluralistic control mode these k-factor values must be communicated to the control block UCTE oh - policy 1 : load-frequency control - final version (approved by sc on 19 march 2009) operator.

The control block operator will then verify whether the total sum of the new k-factors kri involved in the transaction is equal to the total sum of the original $k$-factor values. a-s4. Primary control reserve characteristics. The primary control reserve needs to have certain characteristics to be usable for primary control. availability of reserves. as a minimum in an undisturbed situation, the mandatory primary control reserve for each control area must be available continuously without interruption, not depending on the unit commitment in detail. primary and secondary control reserves must be available for activation independently. a-s4.2. operational usability of reserves.

The mandatory primary control reserve for each control area must be fully activated in response to a quasi-steadystate frequency deviation of $200 \mathrm{MHZ}$ or more bordercrossing primary control reserve. Exchange of reserves for primary control crossing the border of the control area can only be allowed if the concerned tsos have previously confirmed this exchange and if the reserve is exchanged directly between adjacent control areas or remains inside the same control block. Additional power flows induced by cross-border primary control reserve activation have to be considered in the determination of the capacity reliability margin. each tso has to consider worst case conditions for the primary control power flow contribution of primary control reserve to one control area. Individual generation units or individual loads may only deliver primary control reserve / power to one control area at any time, primary control may not be split for different control areas.

A generation unit or load can only have obligations to one reserve receiving tso at any time to assure transparent verification of primary control contributions from a generation unit or load to the single reserve receiving tso. a-s4.5 minimum amount of primary control reserves within control areas / blocks. each tso must declare to the "tso-forum" on annual basis the individual minimum amount of the primary control reserves that needs to be kept within the control area / block due to security needs (as a share a-s4.6. maximum amount of primary control reserves transferred from control areas / blocks. each tso must declare to the "tso-forum" on annual basis the individual maximum amount of the primary control reserves that can be transferred safely to other control areas out of the UCTE oh - policy 1: load-frequency control - final version own control area. monitoring of redistribution of primary control reserves. since the redistribution of primary control reserve is a global topic that affects all tsos, any change in the distribution of primary control reserves outside of the control area and control block needs to be declared to the "tsoforum". a-s5. monitoring and observation. a-s5.1. observation of outages. outages in production or consumption exceeding the size of the observation incident are recorded for analysis by the tso. the required information about location, time, size and type of the disturbance / incident is recorded and made available to the members of the association via the "tsoforum". for second level incidents all tsos are obliged to submit information on their primary contribution to the “tso forum”.a-s5.2. cross-border reserves. 
Monitoring must be executed by the reserve connecting TSO. Monitoring is based on the frequency measurement and the generation unit or load active power measurements, located at the network injection point in the network of the reserve connecting tso.a-s5.3. Measurement cycle for frequency observation. the cycle for measurements of the system frequency for control area observation must be in the range of 1 second (strongly recommended) to at most 10 seconds. the values of the incident sizes are determined and proposed by the "tsoforum” and need approval by all UCTE members.

Determination of overall network power frequency characteristic. the final value of the overall network power frequency characteristic is determined by the "tso-forum" on a regular basis, contribution coefficients determination. the contribution coefficients are determined and published annually for each control area / block the contribution coefficients are binding for the corresponding interconnection partner / tso for one calendar year. They are based on the share of the energy generated within one year in proportion to the entire synchronous area the sum of all contributions coefficients must amount to 1 the "tsoforum" determines and decides about the contribution coefficients of each control area / block for the loadfrequency control area on an annual basis and sets these values into operation on the 1st of January of the next year. a-g4 constant network power frequency characteristic. in order to ensure that the principle of joint action is observed, the network power frequency characteristics of the various control areas is taken to remain as constant as possible.

This applies particularly to small frequency deviations, where the "dead bands" of generators may have an unacceptable influence upon the supply of a-g5. Contracting primary reserve in a neighboring control area or inside a control block: a tso may contract primary reserve in a neighboring control area or inside a control block.

Contracts for providing this service may be signed as tso-tso or as tso-gen co. this implies that an agreement between the concerned tsos has been signed, e.g. concerning the setting of the k-factors on the secondary controller the "tso-forum" will perform simulations to check the consequences for the overall system security on an annual basis. as a result, ultimate limits can be given to individual tsos. Contracting primary reserve in a neighboring control area / block. control performance measurement. the network power frequency characteristic is calculated in response to a disturbance (such as an observation incident), based on measurements of the system frequency and other key values and on a statistical analysis. results of the control performance analysis on a regular basis in the "regular report of the performance of the primary and secondary load-frequency control”, prepared by the "tso-forum". UCTE oh - policy 1: loadfrequency control.

\section{Automatic Voltage Controller}

\subsection{Introduction}

A voltage regulator is an electrical regulator designed to automatically maintain a constant voltage level. A voltage regulator may be a simple "feed-forward" design or may include negative feedback control loops. It may use an electromechanical mechanism, or electronic components. Depending on the design, it may be used to regulate one or more AC or DC voltages.

Electronic voltage regulators are found in devices such as computer power supplies where they stabilize the DC voltages used by the processor and other elements. In automobile alternators and central power station generator plants, voltage regulators control the output of the plant. In anelectric power distribution system, voltage regulators may be installed at a substation or along distribution lines so that all customers receive steady voltage independent of how much power is drawn from the line.

The output voltage can only be held roughly constant; the regulation is specified by two measurements: load regulation is the change in output voltage for a given change in load current (for example: "typically $15 \mathrm{mV}$, maximum $100 \mathrm{mV}$ for load currents between $5 \mathrm{~mA}$ and $1.4 \mathrm{~A}$, at some specified temperature and input voltage").line regulation or input regulation is the degree to which output voltage changes with input (supply) voltage changes - as a ratio of output to input change (for example "typically $13 \mathrm{mV} / \mathrm{V}$ "), or the output voltage change over the entire specified input voltage range (for example "plus or minus $2 \%$ for input voltages between $90 \mathrm{~V}$ and $260 \mathrm{~V}, 50-60 \mathrm{~Hz}$ ).

Other important parameters are: Temperature coefficient of the output voltage is the change in output voltage with temperature (perhaps averaged over a given temperature range), while.

Initial accuracy of a voltage regulator (or simply "the voltage accuracy") reflects the error in output voltage for a fixed regulator without taking into account temperature or aging effects on output accuracy.

Dropout voltage is the minimum difference between input voltage and output voltage for which the regulator can still supply the specified current. A Low Drop-Out (LDO) regulator is designed to work well even with an input supply only a Volt or so above the output voltage. The input-output differential at which the voltage regulator will no longer maintain regulation. Further reduction in input voltage will result in reduced output voltage. This value is dependent on load current and junction temperature.

Absolute maximum ratings are defined for regulator components, specifying the continuous and peak output currents that may be used (sometimes internally limited), the maximum input voltage, maximum power dissipation at a given temperature, etc. Output noise (thermal white noise) and output dynamic impedance may be specified as graphs versus frequency, while output ripple noise (mains "hum" or switch-mode "hash" noise) may be given as peak-to-peak or RMS voltages, or in terms of their spectra.

Quiescent current in a regulator circuit is the current drawn internally, not available to the load, normally measured as the input current while no load is connected (and hence a source of inefficiency; some linear regulators are, surprisingly, more efficient at very low current loads than switch-mode designs because of this).

Response is reaction of a regulator when a (sudden) change of the load current (called the load transient) or input voltage (called the line transient) occurs. Some regulators will tend to oscillate or have a slow response 
time which in some cases might lead to undesired results. This value is different from the regulation parameters, as that is the stable situation definition. The transient response shows the behaviour of the regulator on a change. This data is usually provided in the technical documentation of a regulator and is also dependent on output capacitance.

\subsection{Electronic Voltage Regulators}

Simple voltage regulator can be made from a resistor in series with a diode (or series of diodes). Due to the logarithmic shape of diode V-I curves, the voltage across the diode changes only slightly due to changes in current drawn. When precise voltage control is not important, this design may work fine.

Voltage regulators operate by comparing the actual output voltage to some fixed reference voltage. Any difference is amplified and used to control the regulation element in such a way as to reduce the voltage error. This forms a negative feedback control loop; increasing the open-loop gaintends to increase regulation accuracy but reduce stability (avoidance of oscillation, or ringing during step changes). There will also be a trade-off between stability and the speed of the response to changes. If the output voltage is too low (perhaps due to input voltage reducing or load current increasing), the regulation element is commanded, up to a point, to produce a higher output voltage-by dropping less of the input voltage (for linear series regulators and buck switching regulators), or to draw input current for longer periods (boost-type switching regulators);

If the output voltage is too high, the regulation element will normally be commanded to produce a lower voltage. However, many regulators have over-current protection, so that they will entirely stop sourcing current (or limit the current in some way) if the output current is too high, and some regulators may also shut down if the input voltage is outside a given range (see also: crowbar circuits

\subsection{Electromechanical Regulators}

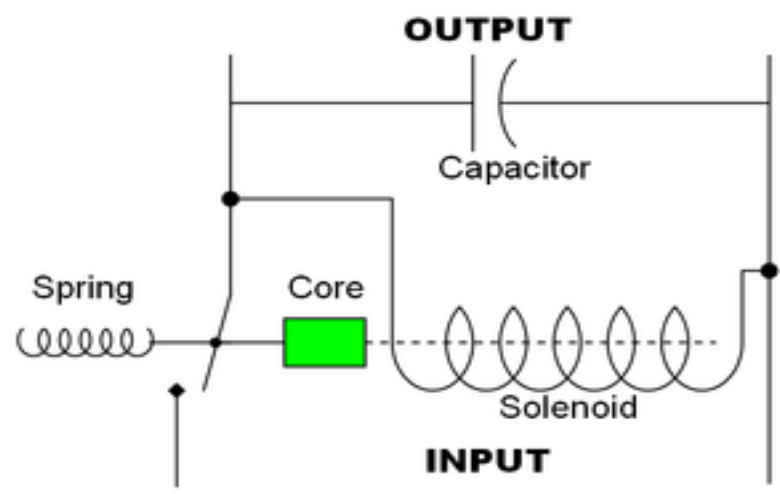

Figure 3.1. Circuit design for a simple electromechanical voltage regulator

In electromechanical regulators, voltage regulation is easily accomplished by coiling the sensing wire to make an electromagnet. The magnetic field produced by the current attracts a moving ferrous core held back under spring tension or gravitational pull. As voltage increases, so does the current, strengthening the magnetic field produced by the coil and pulling the core towards the field.
The magnet is physically connected to a mechanical power switch, which opens as the magnet moves into the field. As voltage decreases, so does the current, releasing spring tension or the weight of the core and causing it to retract. This closes the switch and allows the power to flow once more.

If the mechanical regulator design is sensitive to small voltage fluctuations, the motion of the solenoid core can be used to move a selector switch across a range of resistances or transformer windings to gradually step the output voltage up or down, or to rotate the position of a moving-coil AC regulator.

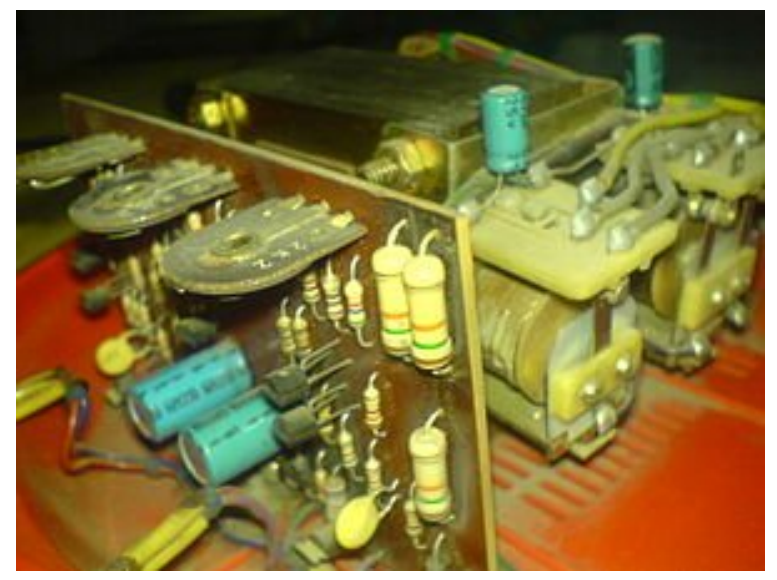

Figure 3.2. a voltage stabilizer using electromechanical relays for switching

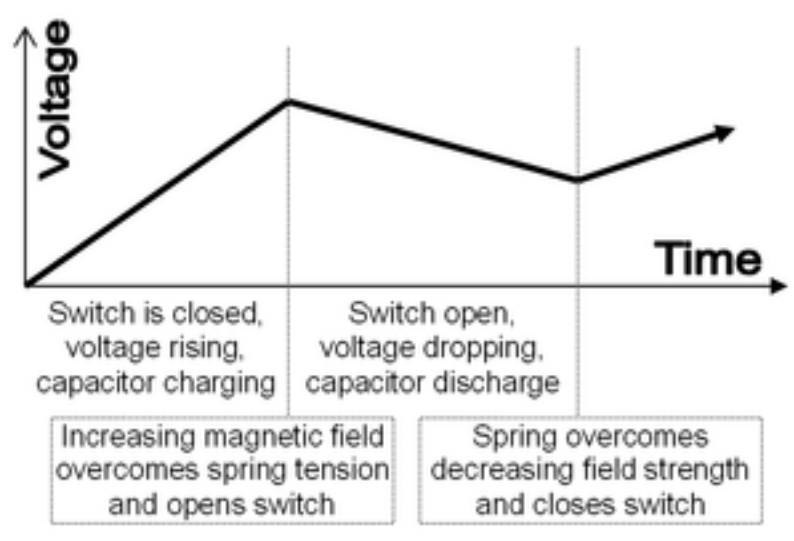

Figure 3.3. Graph of voltage output on a time scale

Early automobile generators and alternators had a mechanical voltage regulator using one, two, or three relays and various resistors to stabilize the generator's output at slightly more than 6 or $12 \mathrm{~V}$, independent of the engine's rpm or the varying load on the vehicle's electrical system. Essentially, the relay(s) employed pulse width modulation to regulate the output of the generator, controlling the field current reaching the generator (or alternator) and in this way controlling the output voltage produced.

The regulators used for DC generators (but not alternators) also disconnect the generator when it was not producing electricity, thereby preventing the battery from discharging back into the generator and attempting to run it as a motor. The rectifier diodes in an alternator automatically perform this function so that a specific relay is not required; this appreciably simplified the regulator design. 
More modern designs now use solid state technology (transistors) to perform the same function that the relays perform in electromechanical regulators.

\subsection{Coil-rotation AC Voltage Regulator}

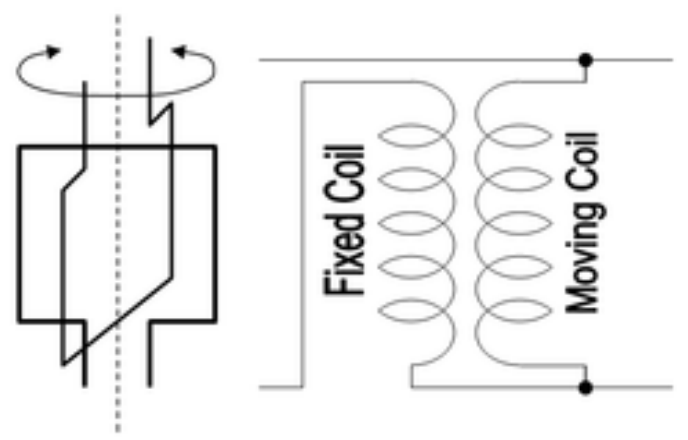

Figure 3.4. Basic design principle and circuit diagram for the rotatingcoil AC voltage regulator

This is an older type of regulator used in the 1920s that uses the principle of a fixed-position field coil and a second field coil that can be rotated on an axis in parallel with the fixed coil.

When the movable coil is positioned perpendicular to the fixed coil, the magnetic forces acting on the movable coil balance each other out and voltage output is unchanged. Rotating the coil in one direction or the other away from the center position will increase or decrease voltage in the secondary movable coil.

This type of regulator can be automated via a servo control mechanism to advance the movable coil position in order to provide voltage increase or decrease. A braking mechanism or high ratio gearing is used to hold the rotating coil in place against the powerful magnetic forces acting on the moving coil.

\subsection{AC Voltage Stabilizers}

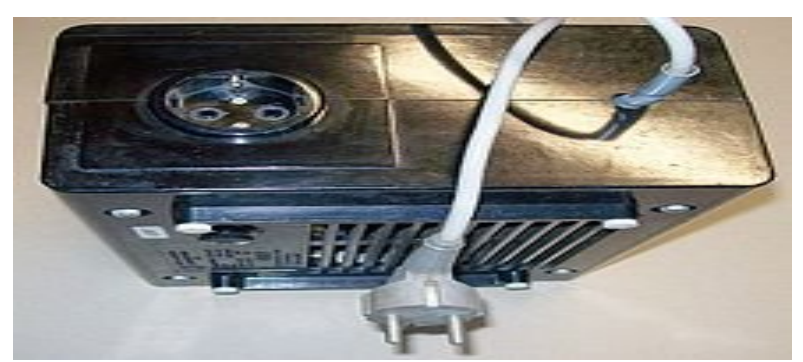

Figure 3.5. Magnetic mains regulator Electromechanical

Electromechanical regulators, usually called voltage stabilizers, have also been used to regulate the voltage on AC power distribution lines. These regulators operate by using a servomechanism to select the appropriate tap on an autotransformer with multiple taps, or by moving the wiper on a continuously variable autotransformer. If the output voltage is not in the acceptable range, the servomechanism switches connections or moves the wiper to adjust the voltage into the acceptable region. The controls provide a deadband wherein the controller will not act, preventing the controller from constantly adjusting the voltage ("hunting") as it varies by an acceptably small amount.

The ferroresonant transformer, ferroresonant regulator or constant-voltage transformer is a type of saturating transformer used as a voltage regulator. These transformers use a tank circuit composed of a high-voltage resonant winding and a capacitor to produce a nearly constant average output voltage with a varying input current or varying load. The circuit has a primary on one side of a magnet shunt and the tuned circuit coil and secondary on the other side. The regulation is due to magnetic saturation in the section around the secondary.

The ferroresonant approach is attractive due to its lack of active components, relying on the square loop saturation characteristics of the tank circuit to absorb variations in average input voltage. Saturating transformers provide a simple rugged method to stabilize an AC power supply.

Older designs of ferroresonant transformers had an output with high harmonic content, leading to a distorted output waveform. Modern devices are used to construct a perfect sine wave. The ferroresonant action is a flux limiter rather than a voltage regulator, but with a fixed supply frequency it can maintain an almost constant average output voltage even as the input voltage varies widely.

The ferroresonant transformers, which are also known as Constant Voltage Transformers (CVTs) or ferros, are also good surge suppressors, as they provide high isolation and inherent short-circuit protection.

A ferroresonant transformer can operate with an input voltage range $\pm 40 \%$ or more of the nominal voltage.

Output power factor remains in the range of 0.96 or higher from half to full load.

Because it regenerates an output voltage waveform, output distortion, which is typically less than $4 \%$, is independent of any input voltage distortion, including notching.

Efficiency at full load is typically in the range of $89 \%$ to $93 \%$. However, at low loads, efficiency can drop below $60 \%$ and no-load losses can be as high as $20 \%$. The current-limiting capability also becomes a handicap when a CVT is used in an application with moderate to high inrush current like motors, transformers or magnets. In this case, the CVT has to be sized to accommodate the peak current, thus forcing it to run at low loads and poor efficiency.

Minimum maintenance is required, as transformers and capacitors can be very reliable. Some units have included redundant capacitors to allow several capacitors to fail between inspections without any noticeable effect on the device's performance.

Output voltage varies about $1.2 \%$ for every $1 \%$ change in supply frequency. For example, a $2 \mathrm{~Hz}$ change in generator frequency, which is very large, results in an output voltage change of only $4 \%$, which has little effect for most loads.

It accepts $100 \%$ single-phase switch-mode power supply loading without any requirement for derating, including all neutral components.

Input current distortion remains less than 8\% THD even when supplying nonlinear loads with more than $100 \%$ current THD.

Drawbacks of CVTs are their larger size, audible humming sound, and the high heat generation caused by saturation. Also, the regulation is not as good as solid state devices, so these units are obsolete for most purposes. 


\subsection{Voltage Stabilizers}

Many simple DC power supplies regulate the voltage using a shunt regulator such as a zener diode, avalanche breakdown diode, or voltage regulator tube. Each of these devices begins conducting at a specified voltage and will conduct as much current as required to hold its terminal voltage to that specified voltage. The power supply is designed to only supply a maximum amount of current that is within the safe operating capability of the shunt regulating device (commonly, by using a series resistor).

If the stabilizer must provide more power, the shunt regulator output is only used to provide the standard voltage reference for the electronic device, known as the voltage stabilizer. The voltage stabilizer is the electronic device, able to deliver much larger currents on demand.

\section{Linear Model of Low-Frequency Oscillation Studies}

\subsection{Introduction}

In this study, the simulation of low-frequency oscillations is based on a single machine connected to infinite bus system. This one machine-infinite bus system with a local load is

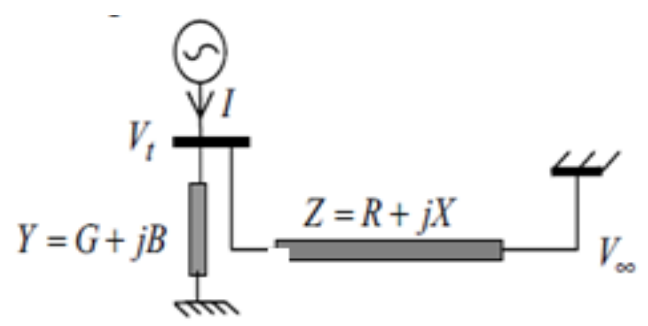

One machine-infinite bus power system.

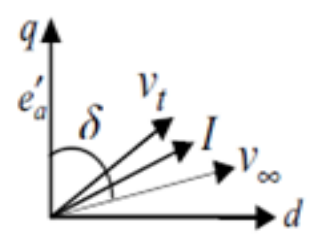

\section{Current and voltage phasors.}

Figure 4.1. one machine infinite bus system

Where, $Z$ : series impedance of transmission line and $Y$ : shunt admittance as a local load. As shown in, the current and voltage phasor is are drawn, and a torque angle defined as the angle between the infinite bus voltage and the $q$ axis. For convenience, the following parameters are introduced:

The magnitude of the generator terminal voltage can be expressed in terms of its $d$ and $q$ components as:

$$
\Delta v_{t}^{2}=v_{d}^{2}+v_{q}^{2}
$$

And the deviation as:

$$
\Delta v_{t}=\left(v_{d}^{0} / v_{t}^{0}\right) \Delta v_{d}+\left(v_{q}^{0} / v_{t}^{0}\right) \Delta v_{q}
$$

Substituting (4.2) into the linearized results of (4.1) and $\Delta v d$ and $\Delta v q$ thus obtained into gives:

$$
\Delta V_{t}=\frac{\partial V_{t}}{\partial \delta} \Delta \delta+\frac{\partial V_{t}}{\partial\left|E_{a}^{\prime}\right|} \partial\left|E_{a}^{\prime}\right|=K_{5} \Delta \delta+K_{6} \partial\left|E_{a}^{\prime}\right|
$$

In this section, the initial values of currents, voltages and their component are all identified by superscript 0 , e.g., 0 id. These initial values in the steady state are usually found from a load flow study. For a one machineinfinite bus system, these values are calculated is case of the electric power, reactive power and the machine terminal voltage are given.

\section{Combined Model for Lfc and Avr Loops in One-Area Power System}

\subsection{Introduction}

The rotational inertia equations describe the effect of unbalance between electromagnetic torque and mechanical torque of individual machines in a LFC system. By having small perturbation and small deviation in speed, the complete swing equation becomes.

$$
\Delta f=\frac{K_{p}}{1+s T_{p}}\left[\Delta P_{m}-\left(\Delta P_{L}+\Delta P_{e}\right)\right]
$$

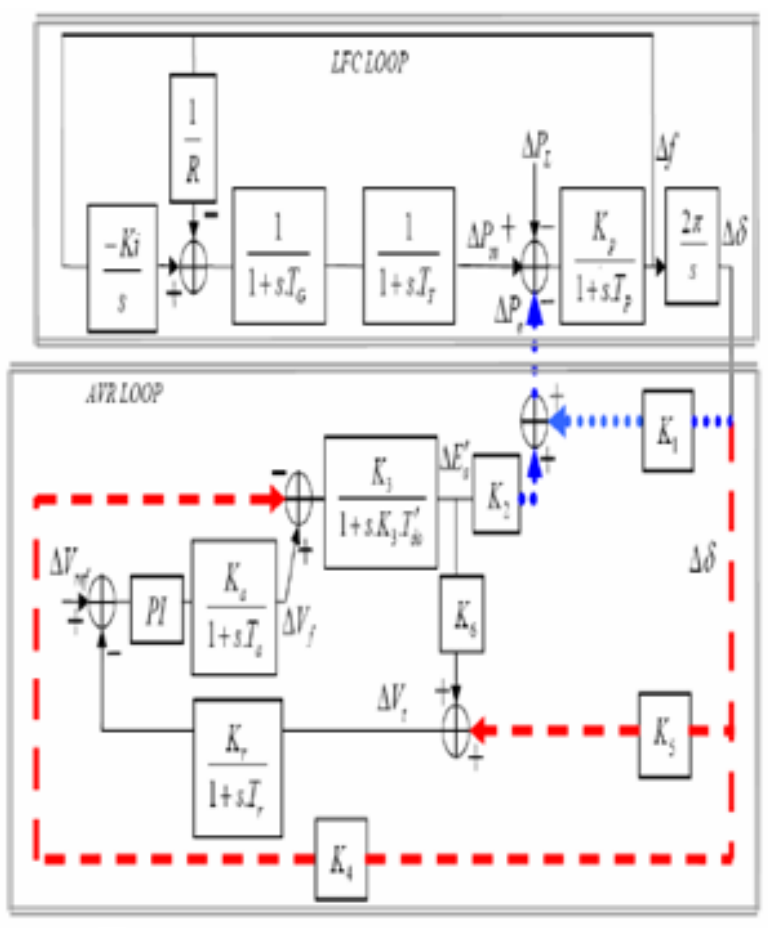

Figure 5.1. proposed combined model for LFC AVR loops

Where, $P e$ is the deviation of internal electrical power that is sensitive to load characteristics. In this section with using (22), (25), (30) and one-area load frequency control system [6], and by substituting $P e$ from(22) into (32), a combined model including load frequency control and AVR system is proposed. This model can be used to show the mutual effect between LFC and AVR loops and depict the slight change in response of turbine output power in the steady state. This proposed model is shown in Figure 4.1. Note that the dashed and dotted lines show the connection between LFC and AVR loops. 


\section{Results}

\subsection{Introduction}

In the simulation study, the combined proposed model is applied for one area power system. To illustrate the performance of this model, simulations are performed for two scenarios of possible operating conditions of a power
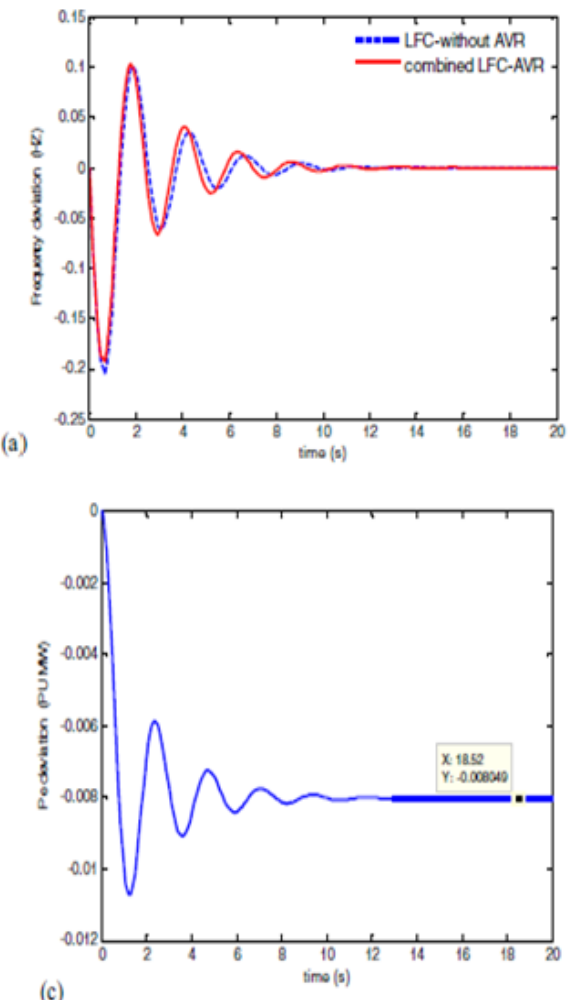

system. In this simulation the performance of the proposed combined model is compared with a classic model of a load frequency control system ignoring AVR loop and excitation system. Note that the simulations are done using platform. Results are shown in following graphs.

\subsection{Scenario}

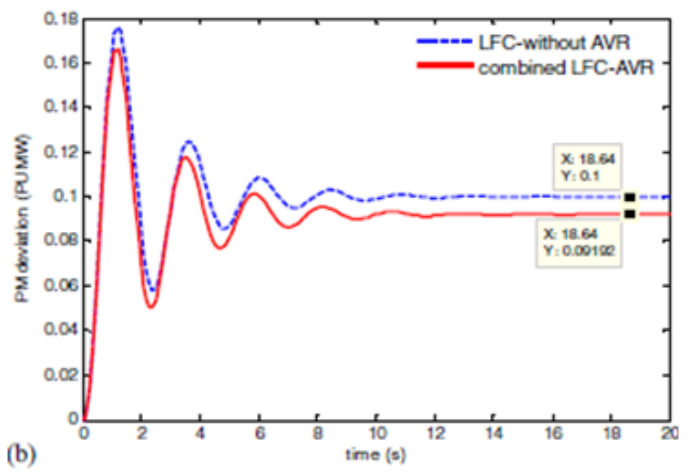

(b)

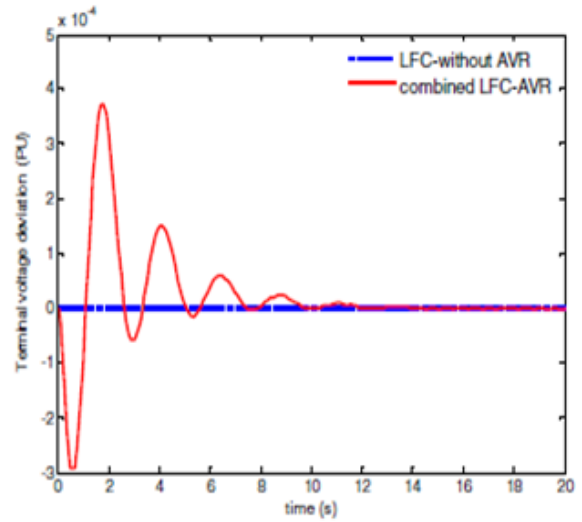

(d)

Figure 6.0. (a) Frequency deviation (rad/s), (b) Turbine output power (pu MW), (c)Terminal voltage deviation (pu), (d) Internal electrical power deviation (pu) (Results for this operating condition: $P=0.9 \mathrm{pu}, Q=0.5 \mathrm{pu}, V t=1 \mathrm{pu}$ )
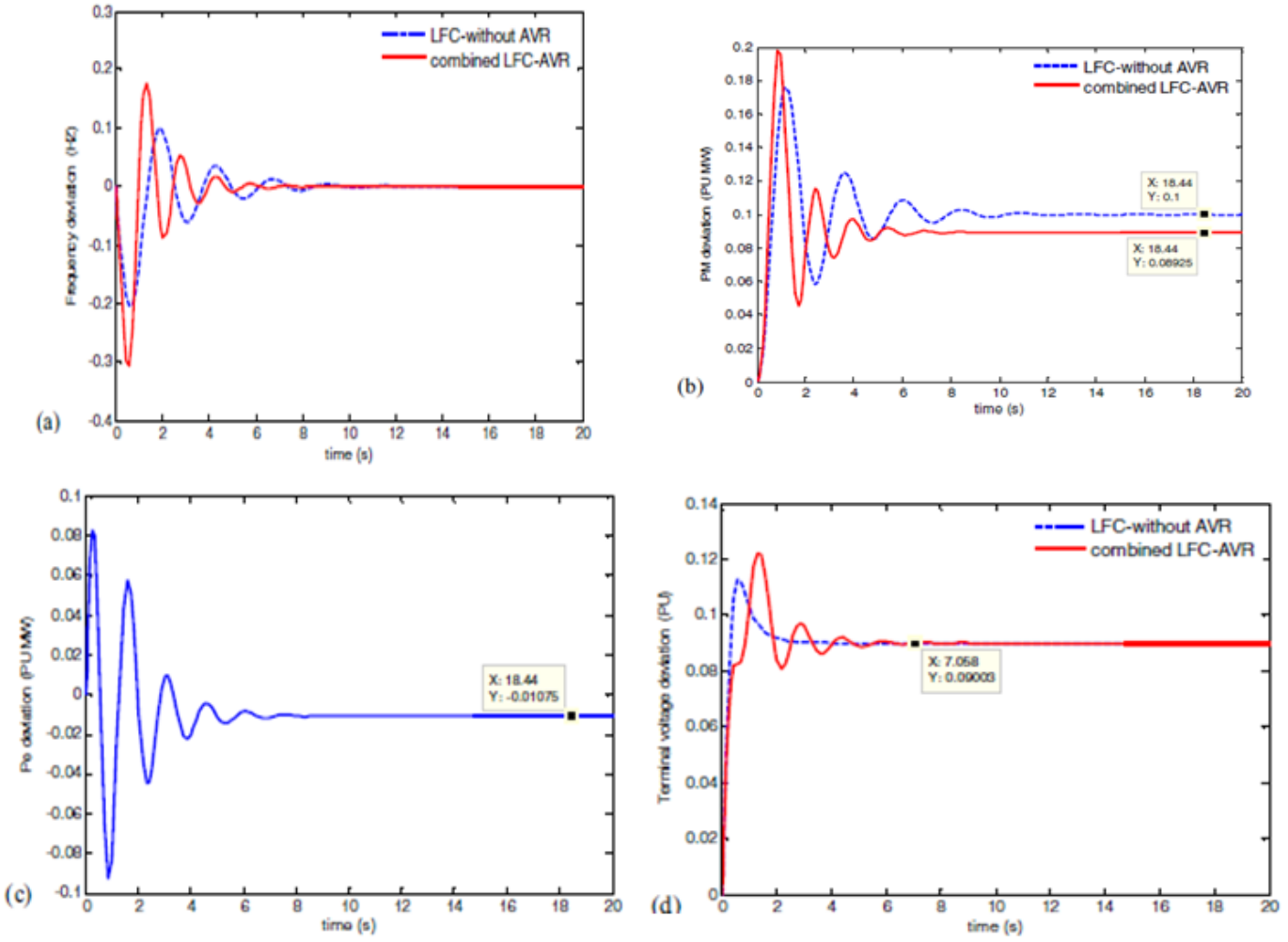

Figure 6.1. (a) Frequency deviation (rad/s), (b) Turbine output power (pu MW), (c)Terminal voltage deviation (pu), (d) Internal electrical power deviation (pu) (Results for this operating condition: $\mathrm{P}=0.9 \mathrm{pu}, \mathrm{Q}=0.61 \mathrm{pu}, \mathrm{Vt}=0.91 \mathrm{pu}$ ) 
In this scenario, it is assumed that the electric power is $0.9 \mathrm{pu}$, reactive power is $0.5 \mathrm{pu}$ and the machine terminal voltage is equal to $1 \mathrm{pu}$. For the LFC system, the load change in real power is set at $10 \%$. Values of the parameters required for this model can be found. The frequency deviation, plant power change, deviation of internal electrical power and deviation of terminal voltage.

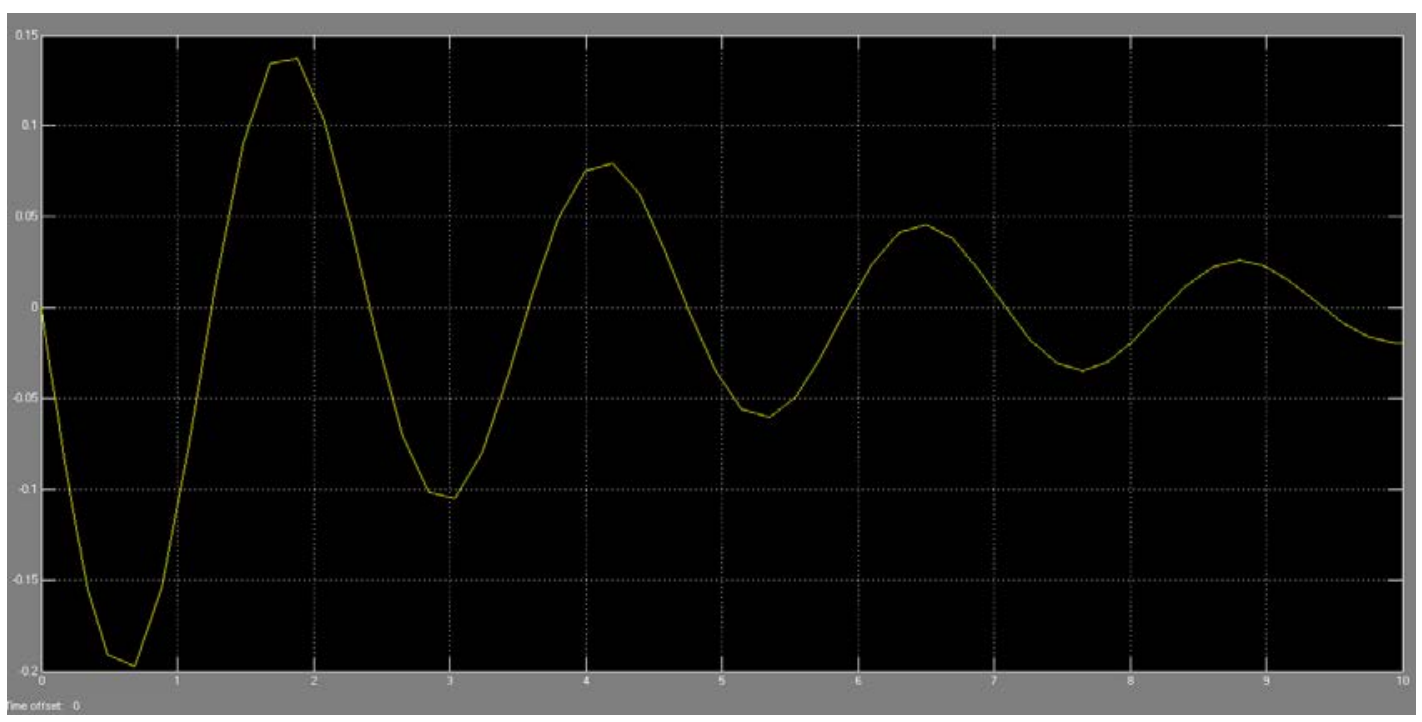

Figure 6.2. FREQUENCY DEVIATION WITHOUT AVR

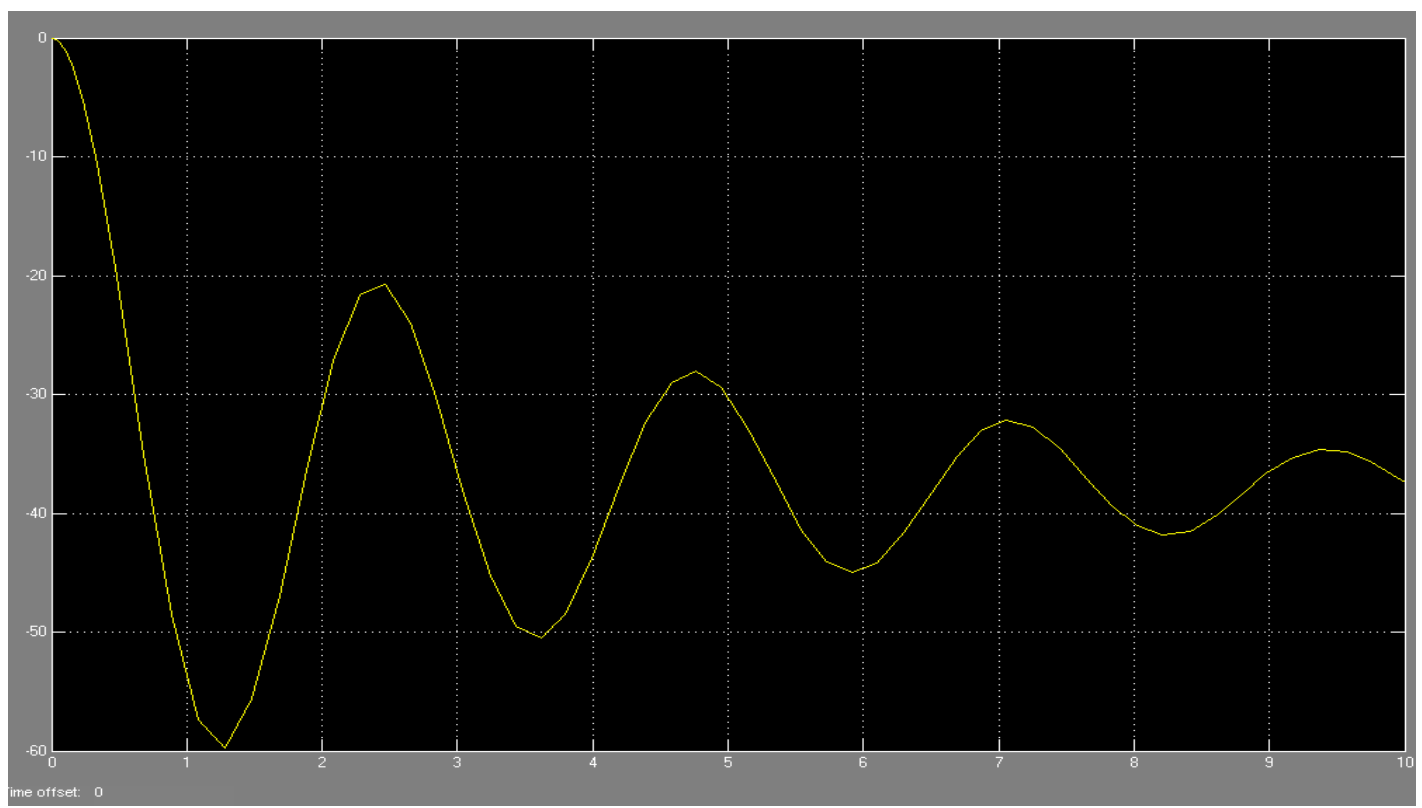

Figure 6.3. PM DEVIATION WITHOUT AVR

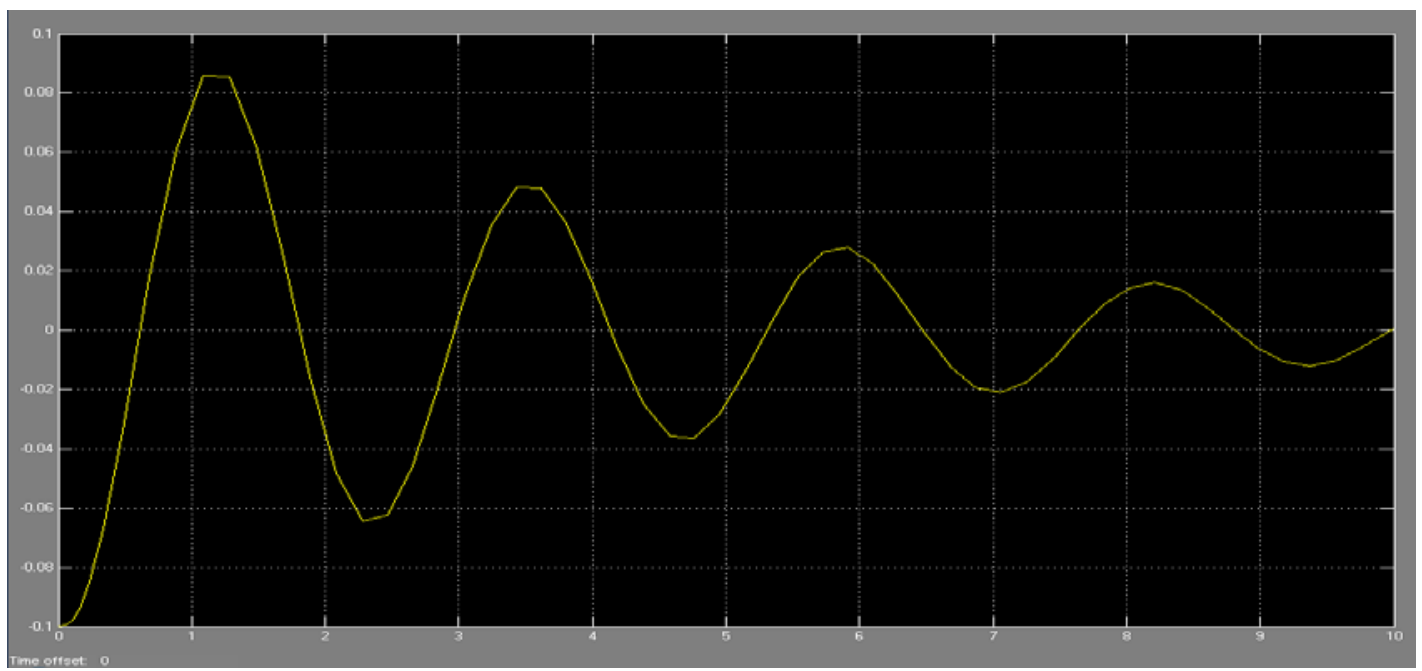

Figure 6.4. PE DEVIATION WITHOUT AVR 


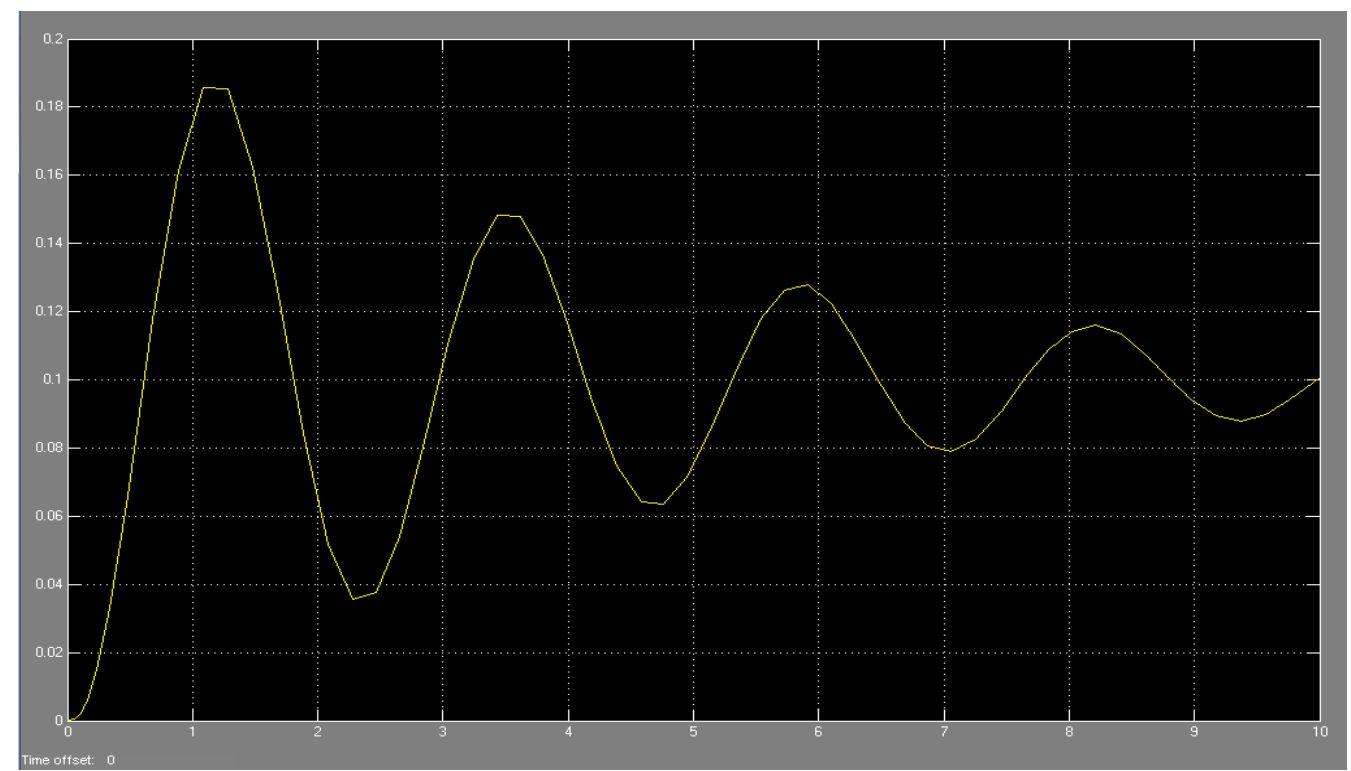

Figure 6.5. TERMINAL VOLTAGE DEVIATION WITHOUT AVR

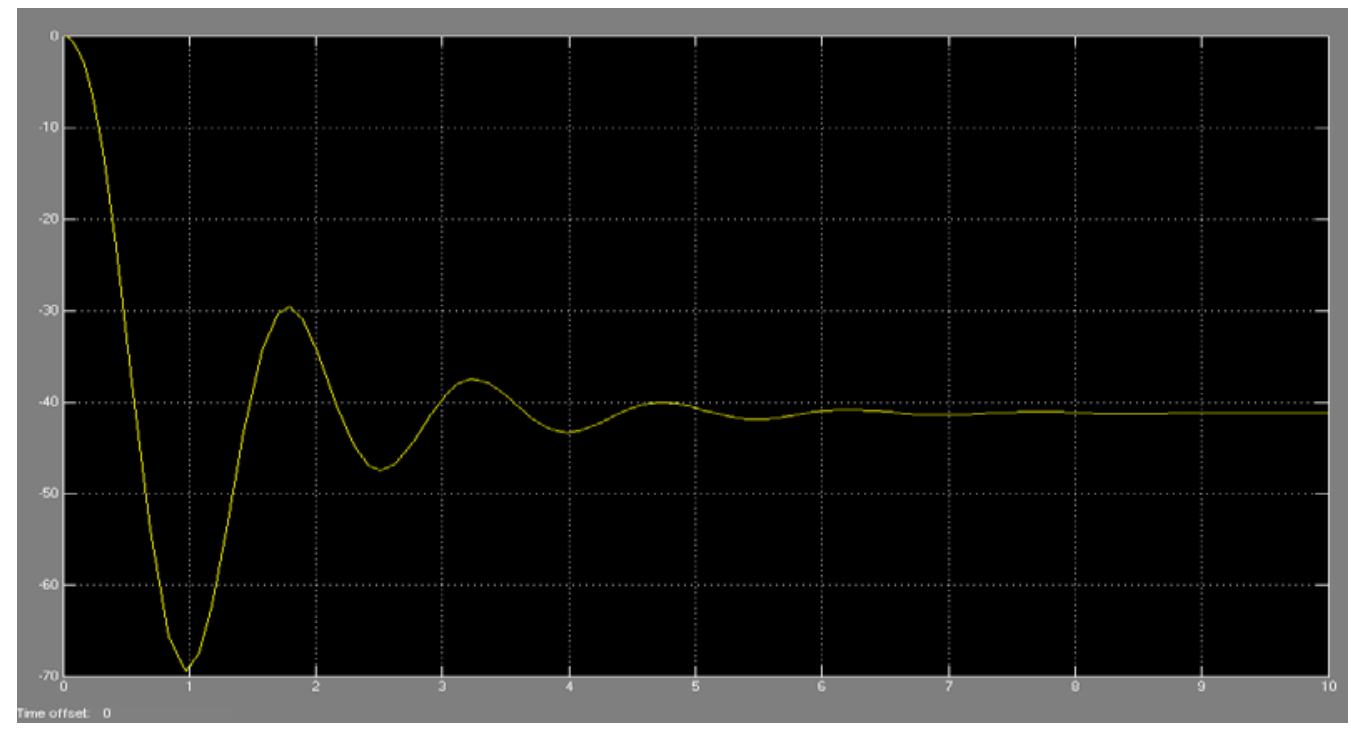

Figure 6.6. FREQUENCY DEVIATIONS COMBINED WITH LFC -AVR LOOPS

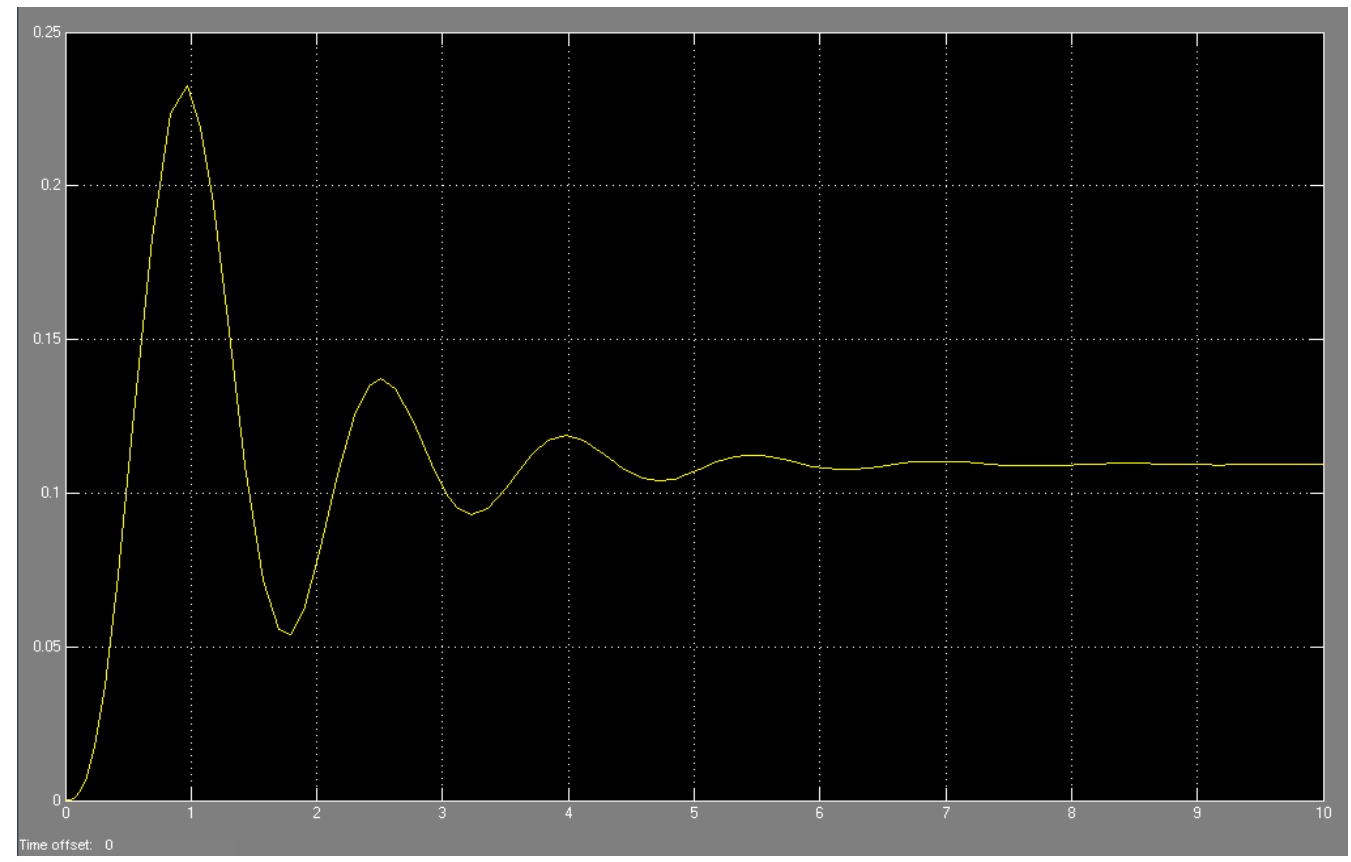

Figure 6.7. PM DEVIATION COMBINED WITH LFC-AVR LOOPS 


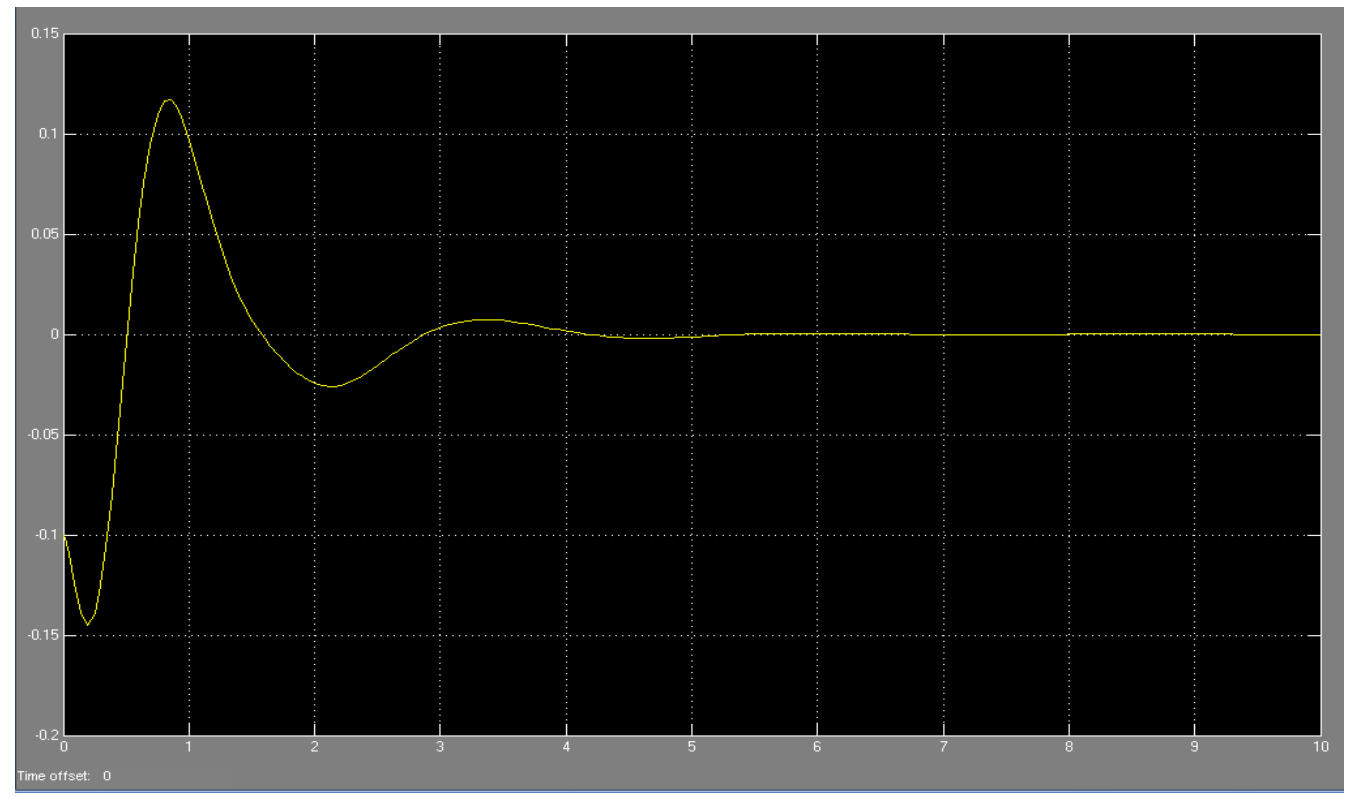

Figure 6.8. PE DEVIATION COMBINED WITH LFC-AVR LOOPS

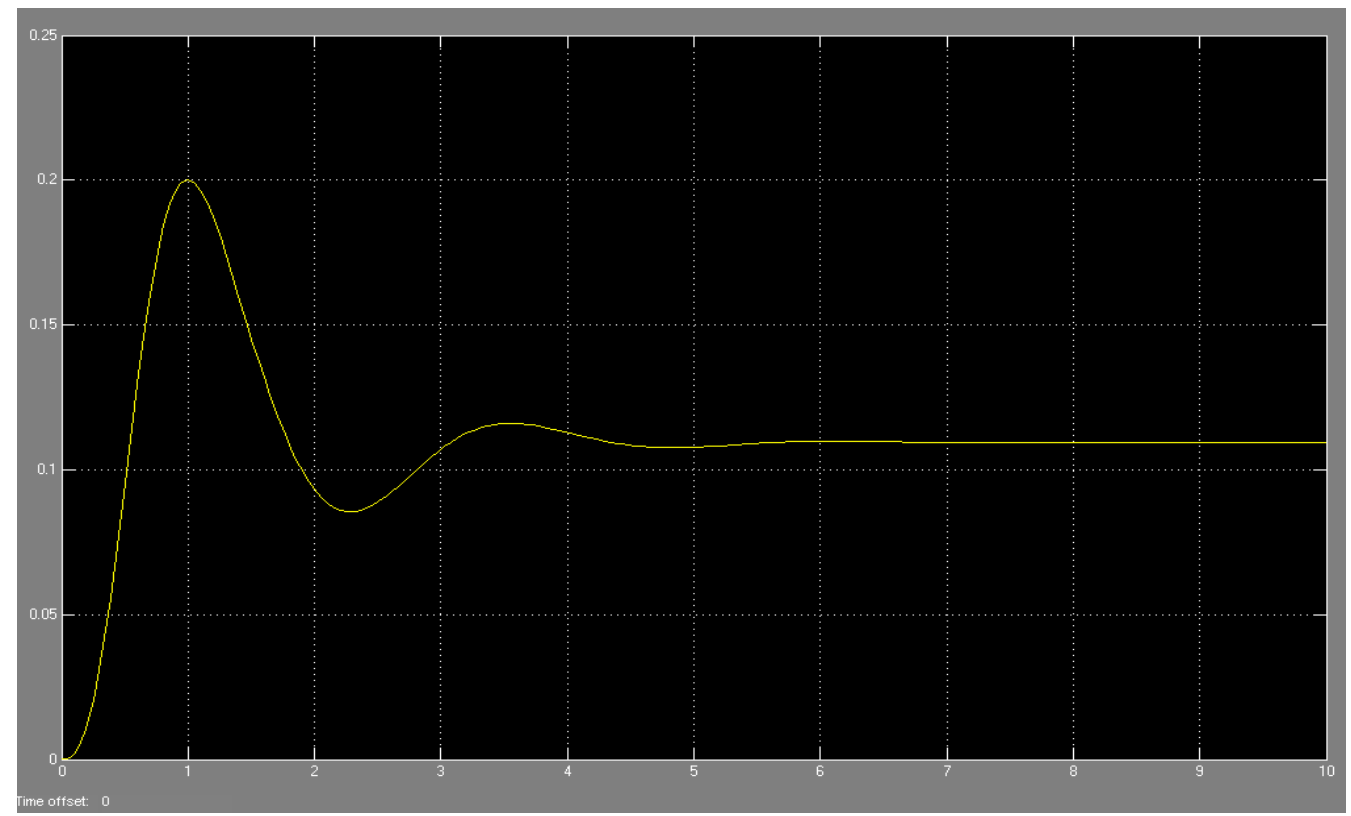

Figure 6.9. TERMINAL VOLTAGE COMBINED WITH LFC-AVR LOOPS

\section{Conclusion}

In this project, by extending the liberalized AGC system to include the excitation system with using onemachine infinite bus model and classic LFC system, a new combined model is proposed. Based on simulations this model shows interaction between the LFC and the AVR loops. This proposed combined model is tested on onearea power system. The results are shown that by using this model more accuracy will be reachable in dynamic and in the steady state responses. The speed governor and the exciter control loops should be considered as interacting loops when a complete study is done. Note that the choice of values for the governor regulation parameter $\mathrm{R}$ and the exciter speed stabilizer gain has a significant effect on the damping of intersystem oscillations as well as area frequencies.

\section{Acknowledgements}

I thank to our Institute Executive directors Mr. T Sai kumar \& Mr. D Baba for providing creative environment for this work. Also I am very much thankful to our Institute principal Dr. K Ramesh for his kind permission and encouragement to write research paper. I would like to extend my heartfelt thanks to my colleagues. And finally I am very much obliged to my respected parents who inspiring me around the clock.

\section{References}

[1] Yau-NaN yu, Electric Power System Dynamics, London, AcademicPress, 1983.

[2] S. C. Tripathy, N. D. Rao, and L. Roy, "Optimization of exciter andspeed governor control parameters in stabilizing intersystem 
oscillationswith voltage dependent load Characteristics," Electric Power and EnergySystems, vol. 3, pp. 127-133, Jul. 1981.

[3] K. Yamashita and H. Miyagi, "Multivariable self-tuning regulator forload frequency control system with interaction of voltage on loaddemand," in Proc. 1991 IEE Control Theory and Applications Conf.,vol.138, pp. 177-183.

[4] N. Jaleeli, L.S. VanSlyck, D.N. Ewart, L.H. Fink and A.G. Hoffmann,"Understanding automatic generation control," IEEE Trans. on Power Systems, vol. 7, no. 3, pp. 1106-1112, Aug. 1992.

[5] Ibraheem, P. Kumar and D.P. Kothari, " Recent Philosophies of Automatic Generation Control Strategies in Power Systems," Power IEEE Trans. on Systems, vol. 20, no. 1, pp. 346-357, Feb. 2005.

[6] H. Saadat, Power system analysis, USA: McGraw-Hill; 1999.

[7] J. Sadeh and E. Rakhshani, "Multi-area load frequency control in a deregulated power system using optimal output feedback method," $5^{\text {th }}$ International Conference on European Electricity Market, May. 2008.

[8] E. Rakhshani and J. Sadeh, "Simulation of two-area AGC system in a competitive environment using reduced-order observer method," $5^{\text {th }}$ International Conference on European Electricity Market, May. 2008.

[9] P. Kundur, Power System Stability and Control, McGraw-Hill Inc., 199.
[10] O.I.Elgerd and C.E.Fosha presents the development of state variable model of the megawatt frequency control problem of multi-area electric energy systems and applications of theorems of modern optimal control theory.

[11] Ibrahim and P Kumar paper presents a comprehensive study on dynamic performance of two area power system when subjected to parameter uncertainties.

[12] M.M. Adibi, J.N. Borkoski, R.J. Kkafka, and T.L. Volkman present the frequency response rates and reserve rates developed for typical combustion turbines, steam electric units and hydro electric units.

[13] N.N.Benjamin and W.C.Chan presents a two level optimal control for the load frequency control of inter connected power system using optimal control and multi level system techniques

[14] H. Shayeghi, H. A. Shayanfar, "PSO based neuro-fuzzy controller for LFC design including communication time delays", International Journal on TPE (Technical and Physical Problems of Engineering) IJTPE, Vol. 1, No. 2, pp. 28-36, June 2010.

[15] A. Soundarrajan, Dr. S. Sumathi, C. Sundar, "Particle swarm optimization based LFC and AVR of autonomous power generating system”, IAENG International Journal of Computer Science, Vol. 37, No. 1, 2010.

[16] D. Karaboga, B. Basturk, “A powerful and efficient algorithm for numerical function optimization: Artificial Bee Colony (ABC) algorithm”, Journal of Global Optimization, Springer Netherlands, Vol. 39, No.3, pp.459-471, 2007. 